\title{
INTERFACES DA DISCIPLINA COMO PRODUTORA DE SUJEITOS NA ESCOLA
}

\author{
DISCIPLINE INTERFACES AS A PRODUCER OF SUBJECTS AT SCHOOL
}

\section{INTERFACES DE LA DISCIPLINA COMO PRODUCTORA DE SUJETOS EN LA ESCUELA}

\author{
ARRUDA, Dayana de Oliveira ${ }^{1}$ \\ OSÓRIO, Antônio Carlos do Nascimento²
}

\section{RESUMO}

O artigo problematiza uma dada engrenagem de investimentos institucionais-disciplinares sobre corpos, disposições e comportamentos de sujeitos agrupados no Projeto "Travessia Educacional do Jovem Estudante Campo-Grandense", operacionalizado na Rede Municipal de Ensino de Campo Grande, no estado de Mato Grosso do Sul, na instituição denominada Escola Osvaldo Cruz, como estratégia de escolarização em nível de ensino fundamental para jovens de 15 a 17 anos, transversal à educação de jovens e adultos, com exercícios e dinâmicas singulares. Utilizamos os referenciais teóricometodológicos foucaultianos, principalmente no que tange à disciplina, além de fontes, registros de observações empíricas e documentos institucionais. Como resultado, redimensionamos a existência de discursos e práticas imbricadas em um aparato institucional-escolar que propõe, sob exercícios de proteção, escolarização e guarda, regularizar e disciplinarizar condutas e corpos.

Palavras-chave: Instituição. Escolarização. Sujeito. Disciplina.

\section{ABSTRACT}

The article discusses a given mechanism of institutional-disciplinary investments on the bodies, dispositions and behaviors of subjects grouped in the Project "Educational Passage of the Young Student Campo-grandense", operationalized in the Municipal Education Network of Campo Grande, in the State of Mato Grosso do Sul, at the Osvaldo Cruz School. Schooling strategy at elementary school level for young people aged 15 to 17 , transversal to youth and adult education, with exercises and unique dynamics. We use Foucaultian theoretical-methodological references mainly in what concerns the discipline. They are sources, records of empirical observations and institutional documents. As results, we restructured the existence of discourses and practices imbricated in an institutional-school apparatus that proposes under protective exercises, schooling and custody, regulating and disciplinarizing conducts and bodies.

Keywords: Institution. Schooling. Subject. Discipline.

\section{RESUMEN}

El artículo problematiza un determinado engranaje de inversiones institucionales-disciplinarias sobre cuerpos, disposiciones y comportamientos de sujetos agrupados en el Proyecto "Travesía Educativa del Joven Estudiante Campo-grandense", operacionalizado en la Red Municipal de Enseñanza de Campo Grande, en el Estado de Mato Grosso do Sul , en la institución denominada Escuela Osvaldo Cruz. Estrategia de escolarización a nivel de enseñanza fundamental para jóvenes de 15 a 17 años, transversal a la educación de jóvenes y adultos, con ejercicios y dinámicas singulares. Utilizamos de los referenciales teórico-metodológicos foucaultianos principalmente en lo que se refiere a la disciplina. Constituyen fuentes, registros de observaciones empíricas y documentos institucionales. Como resultados, redimensionamos la existencia de discursos y prácticas imbricadas en un aparato institucional-escolar que propone bajo ejercicios de protección, escolarización y guardia, regularizar y disciplinarizar conductas y cuerpos.

Palabras clave: Institución. Enseñanza. Sujeto. Disciplina.

\footnotetext{
1 Universidade Federal de Mato Grosso do Sul - UFMS - Campo Grande - Mato Grosso do Sul - Brasil

2 Universidade Federal de Mato Grosso do Sul - UFMS - Campo Grande - Mato Grosso do Sul - Brasil
} 


\section{INTRODUÇÃO}

Este texto tem como objetivo problematizar uma dada engrenagem de investimentos institucionais-disciplinares sobre corpos, disposições, gestos e comportamentos nas práticas efetivas e discursos do Projeto intitulado "Travessia Educacional do Jovem Estudante Campo-Grandense" (TRAJE), constituído como estratégia singular de escolarização, operacionalizada na Rede Municipal de Ensino de Campo Grande (REME), no estado de Mato Grosso do Sul, na instituição denominada Escola Osvaldo Cruz.

Este projeto configurava-se como estratégia cujo intento verificado em dispositivos ${ }^{3}$ pedagógicos identificados, acessados e analisados, correspondia ${ }^{4}$, nas configurações dos anos de 2016 e 2017, à (re)inserção escolar, inclusão social e elevação de níveis de escolaridade de sujeitos jovens na faixa etária dos 15 aos 17 anos, pela condição de acesso, permanência e conclusão em um modelo de escolarização considerado diferenciado e ajustado do ensino fundamental regular e sequencial, com discursos, exercícios e dinâmicas particulares. (CAMPO GRANDE, 2011).

O Projeto Traje aglutinava estudantes que a escola - apreendida sob a referida perspectiva de um processo de escolarização regular e sequencial, arranjado e conduzido como verdade por um almejado fluxo contínuo e necessariamente progressivo de ensino e aprendizado na idade certa, conforme padrões e normativas vigentes - não conseguiu ou não desejou fazer permanecer em seus quadros por diferentes fatores e incongruências individuais, sociais e culturais.

Estes determinantes apontaram, como exercícios do mencionado Projeto, a implementação de uma proposta de escolarização dita inclusiva e diferenciada e, portanto, orientada a um seletivo grupo de sujeitos ocupantes de um espaço institucional-escolar reservado a estudantes taxados, e de antemão tipificados para além do processo educativo-escolar de correção de fluxo, como problemáticos, indisciplinados, potenciais criminosos e usuários de drogas, entre outras características.

São (eram) aqueles não recebidos (ou depreciados) por outras escolas. Sujeitos submetidos a uma constante vigilância de caráter repreensivo sob diferentes e aprimoradas tecnologias de controle e tentativas de disciplinamento - inseridos e aglutinados na operacionalidade de uma proposta de recuperação da aprendizagem como direito garantido - mas, em contraponto, relegados a práticas de exclusão, agrupados por um conjunto de atributos que os constituem como marginalizados, sem a devida comprovação. Marginalizações entendidas em seus múltiplos fatores e circunstâncias que, no campo investigado e conforme identificado, embora aflorem em recorrente demasia, menções e

\footnotetext{
3 "O dispositivo é a rede de relações que podem ser estabelecidas entre elementos heterogêneos: discursos, instituições, arquitetura, regramentos, leis, medidas administrativas, enunciados científicos, proposições filosóficas, morais, filantrópicas, o dito e o não dito". (CASTRO, 2016, p. 124).

${ }^{4}$ Imprevisíveis modificações sociais, políticas e culturais pelas quais claramente atravessa(ra)m o campo de estudos compelem destacar que a Escola Municipal Osvaldo Cruz, em face do Projeto Traje, foi recentemente enredada (2018) por transições e modificações no que tange às suas atribuições e concepções políticopedagógicas, público-alvo e respectivas abrangências na oferta de escolarização pública direcionada a sujeitos jovens e adultos, aspectos que potencializam as problematizações e considerações alinhavadas neste texto, que consideramos pertinentes tendo em vista uma realidade e um contexto investigados em suas asperezas e contradições institucionais.
} 
efetivos exercícios de usos de drogas no espaço estudado, não situa tais determinantes como exclusividade ou generalização.

Ao contrário, entendendo a Escola Municipal Osvaldo Cruz e o Projeto Traje em suas interfaces para além de possíveis ênfases ou realces de suas práticas, constatamos outros elementos, não menos relacionados a exercícios que unem uma multiplicidade de sujeitos sob dispositivos que em síntese propõem correções, como as próprias distorções idade/série, dificuldades de aprendizados e apreensão de conteúdos necessários e decorrentes condições de fracassos escolares, ligadas a questões de ordens econômica, social e cultural.

Neste ínterim, e para efeitos das considerações que seguem, entendemos o vasto campo da educação escolar pública em suas atribuições e dinâmicas sociais como aparato aprioristicamente de cunho educativo e formativo, reservado ao ensino e ao aprendizado, bem como à (re)produção e à legitimação de determinados saberes, valores, competências e habilidades. Espaço institucional cujas atribuições inevitavelmente extrapolam propósitos e finalidades de cunhos técnico e pedagógico quando investigado em suas reais operacionalidades e problematizado em vistas a um conjunto estratégico de dispositivos e (outros) propósitos e interesses, pautados enquanto tecnologias de controle e disciplinamento - materializados nos aportes das instituições e suas convenções culturalmente estabelecidas por meio de instrumentos jurídico-educacionais, regimentos e normas.

Mediados por incertezas, questionamentos e rupturas, os sentidos desencadeados pela problematização como recurso inscrito neste texto evidenciam uma dada liberdade de pensamento em Foucault (2010b), pela tarefa de resgatar, questionar e exaurir as condições de existência, regularidade e racionalidade de certas práticas e discursos enquanto objetos de reflexão e análise às maneiras como estão estabelecidas, suas relações de poderes e de saberes em determinados tempo e espaço de domínio local.

Constituídas sob diferentes ajustes, as instituições, além de incorporarem dinâmicas e conflitos da sociedade, atendem a interesses de poderes vigentes, independentemente de seu ordenamento sempre operativo, envolto por (re)arranjos, mecanismos e estratégias que, por sua vez, atravessam não apenas suas finalidades e propósitos, interferindo diretamente na produção e constituição de sujeitos em seus traços e características mais singulares.

Neste caso, segundo Osório (2010a, p. 90):

\footnotetext{
A escolarização se postula por uma prática cultural de interesse pontual, em um locus determinado, criado pela sociedade, destinado a reproduzir os conflitos presentes na organização da sociedade e adequados às rotinas, respaldadas por valores sociais, em outro espaço de saber/poder.
}

Diante disso, identificamos uma trama de relações de caráter institucional-escolar característica em seus próprios termos, processos, condições e ocorrências, e interações e conjunturas singulares, verificadas especialmente durante os intervalos entre aulas e outras atividades realizadas na Escola Municipal Osvaldo Cruz, no período matutino, nas práticas efetivas do Projeto Traje. 
A extensão do estudo que subsidia este texto se configurou em processo como de tipo etnográfico (ANDRÉ, 1995), de caráter empírico-analítico e documental, apresentando como fontes, elementos determinantes do Regimento Escolar (CAMPO GRANDE, 2016), registros e análises de entrevistas individuais e discussões em grupo, realizadas de modo aberto e exploratório, com sujeitos do espaço investigado - estudantes, gestores, coordenadores pedagógicos e docentes - e apontamentos de procedimentos observacionais.

Utilizamos, ainda, como referenciais teórico-metodológicos em Foucault (2014) - no movimento de experimentações empírico-analíticas empreendido -, noções ou categorias embasadas na disciplina e no exame, intrínsecas às relações dispostas sobre tentativas de normalizações disciplinares, empreendidas no bojo de tecnologias que transitam e são atravessadas por vigilâncias hierárquicas, escrita disciplinar (Livros de Ocorrência) e ações de cunho quase sempre moral e assertivo, como as disposições encontradas no Regimento Escolar. (CAMPO GRANDE, 2016).

A educação escolarizada em referência, aplicada nas práticas pedagógicas e curriculares do Projeto Traje, tem em sua configuração exercícios tangenciados pela educação de jovens e adultos transversal aos níveis da educação básica, conforme previsto pela Lei de Diretrizes e Bases da Educação Nacional (LDBEN). (BRASIL, 1996).

Entretanto, suas práticas operativas ocorrem e se (re)configuram de modo flexível e dinâmico, mediante a materialidade de dispositivos pedagógicos específicos, mas, como em qualquer instituição, enquanto "[...] espaço de disposição, arranjo, formação, instrução, educação do corpo e da mente; marcada por princípios, métodos, sistemas e doutrinas". (OSÓRIO, 2010b, p. 101).

Desse modo, a instituição escolar, em sua multiplicidade de interesses, discursos e práticas, que problematizamos em face de uma dada realidade, conjuga em seus significados, interesses e propósitos determinadas demandas, alinhamentos e legitimações de valores do tecido social como um todo, sejam eles individuais e/ou coletivos, mas sempre histórica e culturalmente estabelecidos.

Trata-se de fazer a análise de um "regime de práticas" - as práticas sendo consideradas como o lugar de encadeamento do que se diz e do que se faz, das regras que se impõem e das razões que se dão, dos projetos e das evidências. (FOUCAULT, 2010a, p. 338, grifo do autor).

Práticas dinamicamente apreendidas como ações e respectivos saberes e fazeres reais e não menos concretos de determinados sujeitos tidos como estudantes, agrupados por um conjunto de características consideradas semelhantes, principalmente na relação distorção idade/série, a considerar outros processos de ensino e aprendizado instituídos, tidos como regulares e sequenciais.

Configurações que sustentam uma realidade característica e singular de um espaço escolar atravessado por diferentes subjetividades, trajetórias, movimentos, exercícios e modos multifacetados de vida, atitudes e reações individuais e coletivas, manifestas e aparentes ou não, em um cotidiano demarcado por processos de (in)exclusão - racionalizados por tentativas de controle e disciplinamento. 


\title{
INSTITUIÇÕES E ARRANJOS DISCIPLINARES: ALGUMAS APROXIMAÇÕES TEÓRICAS
}

Enquanto artefato institucional, como outros em suas respectivas finalidades, domínios, sistemas e doutrinas, as características da escola como instituição de ensino em seus reais pressupostos que versam sobre regularizações sociais e culturais de toda ordem, para além de prerrogativas pedagógicas efetivamente relacionadas a processos de ensino e aprendizado, atravessam atribuições e responsabilidades historicamente adquiridas pelo Estado.

Dispositivos políticos, técnicos, pedagógicos e uma série de recomendações e orientações quase sempre impositivas e unilateriais, permitiram organizar (e aprimorar) ao longo do tempo não apenas os espaços escolares em suas delimitações e intervalos físicos, supostamente estruturais. A organização sistemática de uma dada multiplicidade de sujeitos em um ambiente, a princípio de caráter educativo e social, em verdade institucional-escolar, imprimiu de modo uniforme e regular a representação complexa de seu todo como espaço arquitetural, funcional e hierárquico, aparato primordial da judicialização e suas respectivas práticas padronizadas, corretivas, de vigilância e controle, ao que Foucault (2014, p. 144) destaca:

\begin{abstract}
A organização de um espaço serial foi uma das grandes modificações do ensino elementar. Permitiu ultrapassar o sistema tradicional (um aluno que trabalha alguns minutos com o professor, enquanto fica ocioso e sem vigilância o grupo confuso dos que estão esperando). Determinando lugares individuais tornou possível o controle de cada um e o trabalho simultâneo de todos. Organizou uma nova economia do tempo de aprendizagem. Fez funcionar o espaço escolar como uma máquina de ensinar, mas também de vigiar, de hierarquizar, de recompensar.
\end{abstract}

Neste ínterim, emerge a decorrente apropriação do corpo individual, considerado mote destas operações distributivas utilitárias e positivas, calculadas em minuciosos detalhes e refletidas na positividade de seus efeitos e repercussões. O corpo é estabelecido, desse modo, como objeto vital de manipulações e atravessamentos de uma engrenagem que coaduna, orienta e conduz poderes e saberes, exercícios que processualmente se constituem como cruciais, ao localizar, ajustar, singularizar e determinar individualidades em uma evidente trama de multiplicidades em suas diferenças.

Ao problematizar a noção de corpo sob uma perspectiva histórico-política e de inspiração foucaultiana no que tange aos diversos implícitos institucionais, seus arranjos e adequações, que, por sua vez, determinam a constituição-sujeição dos indivíduos em totalidade, Filho e Trisotto (2008, p. 116, grifos dos autores) desmistificam, nesta acepção, qualquer abordagem exclusivamente naturalizante ou biologicista, ao entenderem o corpo em suas múltiplas constituições, processos, condições e investidas sociais, históricas, culturais, econômicas e políticas:

O corpo, este volume concreto, não tem nada de natural - em rigor, não existe 'corpo natural', espontâneo e livre, 'pura potência', anterior a qualquer trabalho da cultura - ele é sempre resultado de investimentos de poder e de enunciações por saberes: sua própria 'natureza' é construída. 
Assim, são regimentados no decorrer dos séculos XVII e XVIII, padronizações, normas e regramentos gerais de dominação e controle sob a conformação de diferentes métodos de sujeição dos indivíduos e seus corpos a diferentes instâncias e organismos sociais, pautados na relação considerada propositiva de docilidade-utilidade elaboradas, articuladas e constantemente aprimoradas como técnicas ou tecnologias de controle e disciplinamento - operacionalizadas na medida em que, conforme Foucault (2014, p. 213), “[...] as disciplinas são o conjunto das minúsculas invenções técnicas que permitiram fazer crescer a extensão útil das multiplicidades fazendo diminuir os inconvenientes do poder que, justamente para torná-las úteis, deve regê-las."

Embora disposto em constante articulação a considerar a simbiose de seus desdobramentos e efeitos na conformação de uma sociedade disciplinar, Foucault (2014) elucida diferenças no entendimento do complexo instituição-disciplina, sendo a primeira considerada em seus esquemas e ciclos de repetição e aplicabilidade como local, repartição, tempo-espaço de que se ocupam e onde são operacionalizadas disciplinaridades, e estas, por sua vez, implicam caminhos e instrumentos tangíveis de exercícios de determinados poderes.

A 'disciplina' não pode se identificar com uma instituição nem com um aparelho; ela é um tipo de poder, uma modalidade para exercê-lo, que comporta todo um conjunto de instrumentos, de técnicas, de procedimentos, de níveis de aplicação, de alvos; ela é uma 'física' ou uma 'anatomia' do poder, uma tecnologia. (FOUCAULT, 2014, p. 208, grifos do autor).

Diante da organicidade e aplicabilidade de mecanismos disciplinares, seus desdobramentos na constituição de indivíduos dóceis e úteis convergem para novas e cada vez mais otimizadas relações de contexto sob as quais somos submetidos e reiteradamente produzidos, constituídos - caminhos que exprimem o que entendemos como disciplinaridades, âmago complexo que sustenta em saberes estabelecidos em dispositivos, que tangenciam regularizações das diferenças e individualidades.

Ao promover ajustamentos institucionais com vistas a comportamentos e ações devidamente regularizadas e concernentes aos espaços que ocupa, e mediante os quais sofre codificações e decodificações constantes, a disciplina e suas políticas ininterruptas de coerções capturam e dispõem multiplicidades inteiras em suas características mais singulares, transformando os corpos em objetos de controle e disciplinamento.

Por intermédio do realinhamento de técnicas e estratégias específicas a determinados espaços e suas (de)limitações, proibições ou obrigações, consideradas cada vez mais aprimoradas - embora nem sempre sutis, a depender de interesses e conveniências -, a disciplina (ou a implícita necessidade de) estabelece mecanismos cerceadores, de vigilância e controle, específicos a cada um dos espaços e tempos (institucionais) que visa regularizar.

As mencionadas tecnologias de controle e disciplinamento nas operatividades institucionaisescolares, estão configuradas em movimentos constantes e não menos dinâmicos de ajustes e 
(re)elaborações em face de determinados interesses e propósitos reais, que visam garantir estruturas de poderes vigentes, articulados e representados sob discursos de superação, guarda, proteção e outras pretensas garantias e resolutividades de recorrentes problemas sociais postos.

Não há possibilidades de dissociações - a escola problematizada em seus espaços, fronteiras e influências políticas e sociais, delimitações, códigos e diposições, vislumbrados no conjunto de suas práticas exercidas cotidianamente, está configurada como locus privilegiado, engrenagem típica que movimenta e inova poderes disciplinares.

A instituição escolar está inserida nessa sociedade disciplinar, em relações sociais complexas e não há como a isolar desse mundo, não há como fazer do instante pedagógico uma ação autônoma no sentido de deslocamento das influências mundanas e de todo o cotidiano. (SILVEIRA, 2013, p. 210).

As práticas exercidas, problematizadas no Projeto Traje como eixos de reflexão e análise que atravessam este artigo, engendram modos de saberes e fazeres específicos a uma determinada conjuntura e suas múltiplas relações, enquanto exercícios recorrentes de controles e ajustamentos da vida cotidiana, outorgados à instituição escolar mesmo que por determinados períodos ou momentos do dia. Conforme Foucault (2015a, p. 12), "O Estado torna-se assim o agente essencial da moralidade, da vigilância, e do controle ético-jurídico".

No contexto do Projeto mencionado, locus destas interfaces, tais prescrições abarcam dispositivos pedagógicos que sugerem uma funcionalidade dinâmica não previsível, estrategicamente configurada em uma racionalidade política e econômica que desnaturaliza propósitos edificados por discursos ideativos, o que possibilitou (re)pensar suas práticas efetivas na pluralidade de suas condições (outras) de existência - enquanto engrenagem específica de investimentos sobre corpos, para além de processos e propósitos de cunho técnico e pedagógico.

\section{DISCIPLINAMENTOS: PRÁTICAS E SUJEITOS NO PROJETO TRAJE}

A disciplina 'fabrica' indivíduos; ela é a técnica específica de um poder que toma os indivíduos ao mesmo tempo como objetos e como instrumentos de seu exercício. Não é um poder triunfante que, a partir de seu próprio excesso, pode-se fiar em seu superpoderio; é um poder modesto, desconfiado, que funciona a modo de uma economia calculada, mas permanente. (FOUCAULT, 2014, p. 167, grifo do autor).

O Regimento da Escola Municipal Osvaldo Cruz, pelas tentativas de aplicabilidade no cotidiano do Projeto Traje, corresponde ao dispositivo considerado jurídico-educacional que visa regulamentar estratégias administrativas, didático-pedagógicas, disciplinares e, em decorrência, repreensivas e punitivas, com vistas a legitimar os exercícios correntes no mencionado espaço enquanto território composto por multiplicidades. (CAMPO GRANDE, 2016). 
Os efeitos previstos neste documento institucional, a depender de sua operacionalidade e aplicabilidade, no que concerne a um misto de disposições disciplinares e, principalmente, consideradas prescritivas e coercitivas, estão relacionados a proibições orientadas aos estudantes do mencionado Projeto, problematizadas em suas interfaces e no bojo de uma engrenagem operativa de investimentos sobre corpos, disposições, gestos e comportamentos.

Correspondem, no mencionado documento, pontos determinantes que dizem respeito à Seção IV das penalidades (CAMPO GRANDE, 2016, p. 51):

\begin{abstract}
Art. 178. O aluno que infringir as normas deste regimento e violar as disposições da legislação vigente aplicáveis à criança e ao adolescente estará sujeito às seguintes penalidades: I advertência verbal; II - advertência escrita; III - aplicação de atividades com fins educativos; IV suspensão assistida e orientada de até três dias consecutivos. [...]. $\S 7^{\circ} \mathrm{A}$ penalidade de suspensão assitida e orientada ocorrerá após a aplicação das penalidades previstas nos incisos I, II e III, ressalvados os casos de agressão física que resultem em lesões corporais. $\S 8^{\circ} \mathrm{A}$ penalidade de suspensão assitida e orientada terá a duração máxima de 3 (três) dias e deverá ser aplicada pela direção com apoio e orientação da equipe técnico-pedagógica.
\end{abstract}

Os recorrentes exercícios institucionais que demandam diferentes investidas e abordagens repreensivas ou coercitivas da parte de coordenadores, professores e demais agentes institucionaisescolares - como uma rede hierárquica de disciplinamento - são direcionados, sobretudo, a práticas relacionadas ao uso de drogas, como já mencionado, associadas ou não a atitudes consideradas indisciplinadas, como não permanecer nas salas de aula nos momentos estipulados, por exemplo, entremeadas por desobediências a demais regras e desrespeito a funcionários da Escola Osvaldo Cruz.

Estes movimentos cotidianos são atravessados por uma engrenagem de investimentos disciplinares recorrentes, e até mesmo persistentes, enquanto possível sincronia de ocorrências das situações e eventos, em seus desdobramentos de cunho repreensivo e punitivo, de escopo moralizante, a princípio, com fins educativos, portanto, quase sempre sutis.

Ao passo em que a instituição escolar, vislumbrada genericamente, está localizada e representada por uma gama de expectativas, tradições e enquadramentos como aportes intrínsecos aos seus exercícios reais e cotidianos historicamente instituídos, quanto a estas verdades legitimadas por prerrogativas de dispositivos e empenhos considerados como de caráter técnico e pedagógico, destacamos em Foucault (2015b, p. 52, grifo do autor):

\footnotetext{
Cada sociedade tem seu regime de verdade, sua 'política geral' de verdade: isto é, os tipos de discurso que ela acolhe e faz funcionar como verdadeiros; os mecanismos e as instâncias que permitem distinguir os enunciados verdadeiros dos falsos, a maneira como se sancionam uns e outros; as técnicas e os procedimentos que são valorizados para a obtenção da verdade; o estatuto daqueles que têm o encargo de dizer o que funciona como verdadeiro.
}

Verdades são estabelecidas sob inclinações e designações morais da parte de coordenadores pedagógicos, docentes e equipe psicossocial da referida Escola em face ao Projeto Traje, 
considerados responsáveis institucionais, em suas respectivas atuações e atribuições no ordenamento, hierarquia e conjuntura das atividades, por efetivamente visualizarem, reconhecerem, flagrarem e aplicarem determinadas advertências e penalidades a seus modos, mas principalmente por gerirem e administrarem tais episódios e casos em suas ocorrências e regularidades - engrenagens das práticas observadas.

Conforme relatos determinantes do conjunto dos profissionais mencionados, no caso de suspensões serem efetivamente aplicadas à risca e na medida das constâncias de atitudes e ações (in)disciplinadas como constatado, intrínsecas ao ambiente escolar estudado, corre-se o risco da promoção e da incitação, ao contrário da ausência de estudantes em demasia, propiciando o esvaziamento da própria Escola e do Projeto Traje - considerando ainda a dinâmica e o fluxo inconstante de suas frequências, presenças e participações nas aulas e outras atividades oferecidas.

Apontamentos iniciais que corroboram com a ideia de fragilidade da aplicação de tais penalidades e punições como normativas e extensivas, e do próprio Regimento Escolar (CAMPO GRANDE, 2016) em si, no que tange a tais apontamentos, sustentam ainda problematizações delineadas em face das práticas sociais e culturais exercidas no Projeto Traje, mediante as quais foram possíveis outros olhares, interfaces e redimensionamentos, tendo em vista seus exercícios e operatividades concretas, em seus próprios termos, circunstâncias e ocorrências.

Neste sentido, afirma Ratto (2007, p. 77, grifos da autora):

\footnotetext{
Tal lógica é constituída por pressupostos, valores, instrumentos de ação, tradições, objetivos, relações, efeitos, que estão para além das especificidades dessa ou daquela escola. Fazem parte de uma cultura, intra e extra-escolar, que precisa ser problematizada. [...] Nada - a liberdade, a vigilância, a disciplina, os limites, os castigos, a existência de regras ou de normas, assim como qualquer outro valor, princípio ou prática pedagógica - é em si mesmo 'bom' e/ou 'ruim'.
}

Sob tal perspectiva, as ditas tecnologias de controle e disciplinamento foram identificadas enquanto nexos de uma engrenagem, como já ressaltado, que atravessam, conjecturam e marcam os significados do Projeto Traje, justamente pela existência conjunta e simultânea de estratégias de controles e de vigilâncias hierárquicas dirigidas principalmente para o uso de drogas e indisciplinas no interior e adjacências da Escola, conjugadas a um campo documental-descritivo que, por sua vez, comporta registros, traços singulares efetivamente documentados, resguardados como métricas e saberes constituídos em vistas de dados sujeitos (estudantes).

Esta ordenação, um tanto sistemática de exercícios reguladores, denota o que em Foucault (2014) identificamos como economia de poder, uma vez que retrata, e de fato materializa, movimentos estrategicamente dinâmicos não apenas aplicados como configuração de suas atribuições e condições específicas, mas também aprimorados pelas instituições, locus de suas emergências, expressividades e operacionalidades. 
Verificamos que os mecanismos de vigilância hierárquica situados nas práticas estudadas no Projeto Traje, em seus próprios termos e circunstâncias, estão, em verdade, estratégica e sutilmente calculados como composição intrínseca de uma rotina em seus movimentos e dinâmicas singulares, ao passo em que outras vezes, dissolvidos, circulantes e de modo plenamente perceptível e acessível nos espaços físicos, limites internos e todas as extensões possíveis de exercícios inconstantes e imprevisíveis, são característicos do referido Projeto em suas práticas efetivas.

São estratégias distribuídas e orientadas para o cotidiano descumprimento de normas e regras elencadas no Regimento Escolar (CAMPO GRANDE, 2016) enquanto dispositivo jurídico-educacional, da parte de determinados estudantes, seus anseios e modos específicos de estada no ambiente escolar em questão, razão pela qual apreendemos este mesmo documento como referência normativa apenas para descrevê-las enquanto recorrências que angariam certa evidência, com significados e derivações outras, para além de prerrogativas.

Tais normas e regras correspondem a proibições estritas direcionadas ao corpo discente do Projeto Traje, relacionadas a comportamentos, posturas, atitudes, hábitos e demais iniciativas e disposições consideradas incorretas, ilícitas, de consequências negativas e nada apropriadas a um cotidiano escolar que se almeja social, moral, política e pedagogicamente normalizado, devidamente ajustado, disciplinarizado.

Das assim denominadas proibições instituídas, destacamos aquelas que, para além do uso de entorpecentes, durante o processo empírico de estudos e levantamento de informações junto a estudantes, docentes e coordenadores pedagógicos, evidenciamos como exercidas em suas diferenças, proporções e recorrências, as que seguem, listadas no Artigo 177 do Regimento Escolar (CAMPO GRANDE, 2016, p. 50):

\begin{abstract}
É vedado ao aluno: [...] III - Portar e/ou levar, na unidade escolar, armas e explosivos de qualquer natureza, bebidas alcoólicas, entorpecentes e outros objetos estranhos às atividades escolares; IV - fumar, ingerir bebida alcoólica e usar entorpecentes dentro da unidade escolar; V - usar indevidamente aparelho celular ou similares [...]; [...] VII - entrar em sala de aula ou dela sair, sem permissão do professor; VIII - formar grupos com o fim de promover algazarras, incitar os colegas a prática de atos de rebeldia, à prática do bullying, a tumultos nos corredores e pátios da unidade escolar e a movimentos contrários às normas regimentais; IX - desacatar os membros da unidade escolar; XIII - danificar o patrimônio da unidade escolar [...].
\end{abstract}

Identificamos que a regularidade de ocorrências destas condutas em seus diferentes movimentos, embora institucionalmente proibidas, correspondem às possibilidades de concessões, reações e embates travados por estudantes (jovens) do Projeto Traje em contraponto a regularizações, expectativas, ideativos pedagógicos e imposições de toda ordem, evidenciadas na trama de relações que os envolve e atravessa, em meio às quais cotidianamente criam e recriam possibilidades de (sobre)vivência, ainda que por determinado período do dia.

São elementos determinantes que corroboram com a máxima de Foucault (2010b) ao afirmar que onde imperam domínios autoritários sob a ordem de poderes legitimados e tomados por intermédio 
da considerada legítima e instituída existência de regramentos e normas, são evidentes também práticas de liberdade, resistências, enfrentamentos e lutas.

Da mesma forma, tais configurações e exercícios são entendidos como reações - ou, ainda, ações sobre ações - no (des)arranjo de relações fluidas e quase sempre instáveis em processuais modificações, seja entre saberes e poderes em vistas a estudantes, sem necessários pontos irrefutáveis iniciais, finais ou de precisa referência e estabilidade.

Isso significa que, nas relações de poder, há necessariamente possibilidade de resistência, pois se não houvesse possibilidade de resistência - de resistência violenta, de fuga, de subterfúgios, de estratégias que invertam a situação -, não haveria, de forma alguma, relações de poder. (FOUCAULT, 2010c, p. 277).

Diante disso, observamos, como já estabelecidas neste mesmo cotidiano e contexto, e diante destas relações em suas múltiplas configurações e respectivas dinâmicas singulares, a existência de estratégias de vigilância constante, especialmente nos momentos de intervalo e outras atividades em que os estudantes se encontram, a princípio, dispersos e convivendo de modo mais acentuado em pequenos grupos no interior do espaço escolar.

Foram nesses momentos específicos que identificamos, como parte de acontecimentos do Projeto Traje, a prontidão de docentes, coordenadores pedagógicos e outros profissionais não menos atentos, que, por rodízio previamente estabelecido, se revezavam diariamente muito próximos aos banheiros, locais propícios para que determinados estudantes utilizem drogas, na recorrente e persistente tentativa de coibir esta prática de alguma maneira.

Constatamos, nas dimensões e influências múltiplas do espaço estudado, que estas mesmas práticas persistiam agregadas à própria mobilidade dos estudantes, seus contatos, redes de relações, convívios e relacionamentos diversos entre si (por vezes harmônicos e outras vezes conflitivos), estabelecidos em um cotidiano sempre alerta, ativo, operante, a depender de perspectivas e intencionalidades nem sempre de cunho negativo.

Contingências que, ao contrário, não caracterizam pretensões de promover, diante das práticas estudadas em seus próprios termos como condições postas, generalidades em face da Escola Municipal Osvaldo Cruz e do Projeto Traje que, porventura, delimitem e especifiquem indicadores ou quaisquer linhas de reflexão e/ou apontamentos. De fato, operacionalidades que explicitam o cotidiano investigado em suas práticas atravessadas, e desse modo representadas por estudantes em si mesmos, de maneiras positivas ou negativas, possibilitando o desenrolar (ou não) da travessia proposta a princípio como processo de escolarização, mas, sobretudo, de identificações e vinculações perante os demais (outros indivíduos) em suas diferenças quanto a anseios, desejos e perspectivas.

Ao mesmo tempo, o quadro de vigilâncias ininterruptas decorre da utilização de outros instrumentos e técnicas simultaneamente explorados enquanto composição de investimentos aprimorados sobre corpos e comportamentos dirigidos a estudantes, conforme já mencionado, marcas 
reconhecidas nos chamados Livros de Ocorrência - identificados no escopo e nos princípios da escrita disciplinar alinhavada por Foucault (2014).

Quanto à vinculação dos Livros de Ocorrência, acessados em sua funcionalidade cotidiana e reais propósitos como escrita disciplinar utilizada nos exercícios do Projeto Traje, remetemos à categoria analítica e decorrentes leituras e significados que derivam do exame de inspiração foucaultiana e que, neste caso, situa e localiza os indivíduos em um campo documental-descritivo demasiado amplo e, ao mesmo tempo, determinado, fixo.

Entendemos que a utilização assídua de instrumentos como os denominados Livros de Ocorrência em simultaneidade a vigilâncias hierárquicas, nos exercícios institucionais estudados e analisados, esquadrinha e conforma sujeitos em seus atributos mais intrínsecos aos mais genéricos e considerados universais. (FOUCAULT, 2014).

Diante destas tentativas de ajustamentos de caráter individual e coletivo, observamos ainda como aspecto preponderante dos exercícios Escola e do Projeto Traje, uma habitual insistência dos mencionados agentes institucionais (docentes, coordenadores pedagógicos e equipe psicossocial) em sensibilizar os estudantes a retornarem às suas respectivas salas de aula ou atividades após o alerta de término de aproximadamente 15 a 20 minutos reservados ao intervalo - em meio a copiosas negativas em cumprir tal prescrição.

Muitos jovens se mostram resistentes ao encerramento desta pausa, na medida em que relutam em (des)obedecer as regras e voltar às aulas e atividades, insistindo em continuar jogando futebol, conversando e interagindo com colegas ou ainda realizando quaisquer outras práticas considerando ainda que muitos permanecem por longos períodos, seja antes ou depois do intervalo e durante a realização de quaisquer atividades do Projeto, dispersos e alheios a qualquer compromisso.

Eventos e respectivas conjunturas imersas no conjunto já explicitado, investidos por vigilâncias constantes, agregadas à utilização simultânea de registros escritos, que o Projeto Traje denomina Livros de Ocorrência, como já mencionado, seguidas ainda de repreensões de caráter moral-punitivo sob as mais diferentes intensidades e orientações nem sempre sutis e amenas, outras vezes um tanto diretivas e incisivas, forjando e conformando contornos de exercícios de poderes, correspondendo, como analisado, a aprimoradas investidas de normalizações disciplinares.

A operacionalidade desta engrenagem sob a constância de vigilâncias hierárquicas e registros escritos, dispostos em suas flexibilidades, regulações, termos e dinâmicas próprias do(no) ambiente estudado, indica um movimento singular de modificações e adequações a práticas vislumbradas tão somente como pedagógicas, que em seus efeitos e em vistas a mecanismos de seleção e controle instituídos, socialmente outorgados na e pela institucionalização do espaço escolar, não sucedem necessariamente em resolutividades efetivas conforme prescritas em dispositivos.

Neste sentido, estritamente aliada à função de normalizar, compete à Escola Municipal Osvaldo Cruz, em face do Projeto Traje e dos jovens (estudantes) que agrupa, com vistas a um gerenciamento conciso e efetivo de seus exercícios institucionais - administrar e assim regularizar uma multiplicidade 
de desajustes escamoteados por problemáticas alinhadas pela distorção idade/série, no conjunto de suas particularidades, não sendo necessário prescrever penalidades incisivas, mas, de modo perene, acompanhar, manter e gerir, sob o uso de tecnologias de controle e disciplinamento, aqueles a quem governa e indistintamente tenta ajustar e corrigir para além de processos de ensino e aprendizado.

Constatamos com isso que tais tecnologias de controle e disciplinamento, em sua profusão operativa, ao contrário de proceder em vistas a garantias e resolutividades efetivas, sustentam uma engrenagem singular de práticas sociais e culturais instituídas e instituintes no Projeto Traje, envolta de conflitos, queixas, indisciplinas, harmonias, assertivas, esperanças, momentos de descontração, práticas de liberdade, entre tantos aspectos e elementos dinâmicos, enquanto atravessamentos que interpelam determinado jogo de saberes e de poderes, ativo, enérgico e um tanto complexo.

\section{CONSIDERAÇÕES: OUTRAS PERCEPÇÕES}

Pretendemos com este artigo, ao problematizar uma engrenagem de investimentos institucionais-disciplinares sobre corpos, disposições, gestos e comportamentos, desmistificar o limiar de possível fronteira existente entre o que se caracteriza, sumariamente, como proposto no Projeto Traje, a partir de documentos, marcos regulatórios e discursos instituídos - em interface e correlações com práticas exercidas, exploradas em tramas singulares de relações materiais e intersubjetivas, redimensionando o que vislumbramos como (des)locamentos, quais sejam, leituras e domínios descontínuos que em si mesmos sobrepõem limites, pretensões e ideativos pedagógicos.

Diante disso, as tecnologias de controle e disciplinamento, problematizadas como operatividades institucionais-escolares no Projeto Traje, estão configuradas em movimentos constantes de ajustes e (re)elaborações de suas práticas em face de interesses previamente circunscritos, que visam garantir estruturas de poderes vigentes, articulados e rotulados sob discursos de inclusão, dos quais emergem tentativas recorrentes de superação, guarda, proteção, garantidas e resolutividades de problemáticas individuais e sociais postas.

Contraditoriamente, os exercícios intrínsecos entendidos como práticas sociais e culturais do Projeto Traje versam sobre (inter)relações de caráter coletivo e individual, tangenciadas por propósitos aprioristicamente antagônicos aos processos de ensino e aprendizado propostos por interfaces dos dispositivos pedagógicos como assinalado - realidades multifacetadas que transcorrem em meio a concessões, ações sobre ações, ajustes, maneiras difusas e heterogêneas de estada e permanência de estudantes e demais sujeitos a seus modos e possibilidades no espaço-tempo estudado.

No conjunto (des)ordenado das considerações empreendidas, tendo em vista reflexões e análises sobre diferentes âmbitos sociais e seus respectivos espaços historicamente institucionalizados, que, a seus modos, incidem na constituição dos sujeitos, destacamos, a partir dos referenciais foucaultianos (2014), princípios de docilidade-utilidade considerados em suas positividades e investimentos como domínios disciplinares sobre corpos, forças, disposições, atitudes e comportamentos. Para Osório (2007, p. 305-306 - grifos do autor) corresponde a: 
[...] práticas sociais registradas historicamente por ações e processos 'interditos', ou seja, que propõem conjugar a distribuição de normalização, por leis, normas e regras que dão sustentação ao 'poder disciplinar' explícitos ou implícitos na sociedade.

Configuram-se como reiterados discursos e práticas efetivas, que pouco incluem, ou ainda em uma perspectiva contraditória às suas prescrições e finalidades, objetivos e pressupostos, em verdade excluem determinados jovens ao agrupá-los, selecioná-los e ordená-los em um dado espaço singular, sob conjuntos específicos de características, especificidades e marcas, os quais passam a frequentar e compor tal ambiente assim vislumbrado, por motivos, finalidades e disposições alheias e difusas às pretensões e ideativos previamente estabelecidos por interfaces de dispositivos pedagógicos.

Constatamos assim, que o referido Projeto, como espaço institucional escolar específico e local (micro), propõe sob discursos e exercícios cotidianos de tentativas de proteção, escolarização e guarda, investidas incisivas em vistas à regularização de condutas e docilização dos corpos - pela evidente sustentação de uma gama de problemáticas e complexidades políticas, sociais e culturais de âmbito macro, que não se esgotam. Operacionalidades em (des)compasso cotidiano a enfrentamentos, resistências, incidências de liberdade e seus salutares efeitos, engendrados cotidianamente e ainda assim de modos distintos, pelos sujeitos envolvidos.

Entendemos que os exercícios constatados no Projeto Traje conduziram interfaces de uma Proposta unilateralmente pensada não pela real inovação e possíveis melhorias nas condições de vida de seu público-alvo e suas respectivas demandas, anseio e perspectivas um tanto desconhecidas pelas políticas de cunho educativo e assistenciais - jovens considerados excluídos de outros espaços e tempos de formação escolar, amplamente situados no bojo de marginalizações e desigualdades múltiplas, de fatores e ordens sociais, culturais e individuais.

Em contraposição, um Projeto pensado, elaborado e operacionalizado para e pelas condições de exclusão, em uma sistemática própria de seus discursos e exercícios, sobretudo pela adequação de um padrão de educação ou de escolaridade com base em moralidades socialmente instituídas e suas verdades impositivas, que se propõem pragmáticas, corretivas e quase sempre resolutivas, movimentos institucionalizados e por isso regimentados, nos quais versam seus (outros) propósitos e interesses por tentativas de controle, disciplinamento e correção.

Os desdobramentos deste texto, em face das aproximações de caráter empírico-analítico alinhavadas pelos referenciais foucaultianos, convergem esforços à emergência de outros saberes e possibilidades analíticas com vistas a enfrentamentos e resistências, não somente acerca da realidade institucional-escolar investigada em suas singularidades de tempo e espaço, mas também propícios a repensar e problematizar a escola pública contemporânea em suas diferentes e multifacetadas dimensões, acontecimentos reais e (des)locamentos, para além de sua estrutura, funções, propósitos e finalidades consideradas técnicas e pedagógicas, retratadas, prescritas e até mesmo reproduzidas em seus dispositivos, regulamentos e normativas. 


\section{REFERÊNCIAS}

1. ANDRÉ, Marli Eliza Dalmazo Afonso de. Etnografia da prática escolar. 16. ed. Campinas: Papirus, 1995.

2. BRASIL. Lei 9.394, de 20 de dezembro de 1996. Estabelece as Diretrizes e Bases da Educação Nacional. Diário Oficial [da] República Federativa do Brasil, Brasília, DF, de 23 dez. 1996.

3. CAMPO GRANDE [MS]. Regimento Escolar: Eja - TRAJE. Campo Grande, MS, 2016. Secretaria Municipal de Educação. Traje: Travessia Educacional do Jovem Estudante. Projeto diferenciado no ensino fundamental (proposta). Campo Grande, MS, 2011.

5. CASTRO, Edgardo. Vocabulário de Foucault: um percurso pelos seus temas, conceitos e autores. Tradução de Ingrid Müller Xavier. 2. ed. Belo Horizonte: Autêntica Editora, 2016.

6. FOUCAULT, Michel. A sociedade punitiva: curso no Collège de France (1972-1973). Tradução de Ivone C. Benedetti. São Paulo: Editora WMF Martins Fontes, 2015a. Microfísica do poder. 3. ed. Rio de Janeiro: Paz e Terra, 2015b. . Vigiar e punir: nascimento da prisão. Tradução de Raquel Ramalhete. 42 ed. Petrópolis: Vozes, 2014. Mesa-redonda em 20 de maio de 1978. 1980. In: MOTTA, Manoel Barros da (Org.). Ditos e escritos IV: Estratégia, poder-saber. Tradução de Vera Lucia Avellar Ribeiro. Rio de Janeiro: Forense Universitária, 2. ed, 2010a. p. 335-351. O Cuidado com a Verdade. 1984. In: MOTTA, Manoel Barros da (Org.). Ditos e escritos V: Ética, sexualidade, política. Tradução de Elisa Monteiro e Inês Autran Dourado Barbosa. Rio de Janeiro: Forense Universitária, 2. ed, 2010b. p. 240-251. (Org.). Ditos e escritos V: Ética, sexualidade, política. Tradução de Elisa Monteiro e Inês Autran Dourado Barbosa. Rio de Janeiro: Forense Universitária, 2. ed, 2010c. p. 264-287. 
12. FILHO, Kleber Prado; TRISOTTO, Sabrina. O corpo problematizado de uma perspectiva históricopolítica. Psicologia em estudo, Maringá, v. 13, n. 1, p. 115-121, jan./mar. 2008. Disponível em: http://www.scielo.br/pdf/pe/v13n1/v13n1a13.pdf. Acesso em: 20 jun. 2017.

13. OSÓRIO, Antônio Carlos do Nascimento. Escolarização: práticas sociais, culturais e pedagógicas fragmentos de uma realidade seletiva. In: MENDES, Enicéia Gonçalves; ALMEIDA, Maria Amélia (Orgs.). Das margens ao centro: perspectivas para as políticas e práticas educacionais no contexto da educação especial. Araraquara: Junqueira \& Martin Editores, 2010a. p. 89-98. . As instituições: discursos, significados e significantes, buscando subsídios teóricos e metodológicos. In: OSÓRIO, Antônio Carlos do Nascimento (Org.). Diálogos em Foucault. Campo Grande: Oeste, 2010b. p. 95-133.

15. . Estranho medo da inclusão. Educação, v. 32, n. 2, p. 301-318, 2007.

16. RATTO, Ana Lúcia Silva. Livros de ocorrência: (in)disciplina, normalização e subjetivação. São Paulo: Cortez, 2007.

17. SILVEIRA, Marcos Antônio Paz da. O discurso sobre violências nas escolas. In: OSÓRIO, Antônio Carlos do Nascimento (Org.). Poderes e saberes: corpus em educação. Campo Grande: Oeste, 2013.p. 207-223.

\section{Dayana Oliveira Arruda}

Doutoranda em Educação pela Universidade Federal de Mato Grosso do Sul (UFMS). Mestre em Educação (2018) e Bacharel em Ciências Sociais (2009) também pela UFMS. Integra o Grupo de Estudos e de Investigação Acadêmica nos Referenciais Foucaultianos (GEIARF/CNPq).

\section{Antônio Carlos do Nascimento Osório}

Professor Titular dos Programas de Pós-Graduação em Educação (Faculdade de Educação) e Psicologia (Faculdade de Ciências Humanas) da Universidade Federal de Mato Grosso do Sul UFMS. Coordenador do Grupo de Estudos e de Investigação Acadêmica nos Referenciais Foucaultianos (GEIARF/CNPq). Doutor em Educação pela Pontifícia Universidade Católica de São Paulo. 


\section{Como citar este documento:}

ARRUDA, Dayana Oliveira; OSÓRIO, Antônio Carlos do Nascimento. Interfaces da disciplina como produtora de sujeitos na escola. Reflexão e Ação, Santa Cruz do Sul, v. 27, n. 1, dez. 2018. ISSN 1982-9949. Disponível em: <https://online.unisc.br/seer/index.php/reflex/article/view/11727>. Acesso em doi:https://doi.org/10.17058/rea.v27i1.11727. 